\title{
Removal of ibuprofen, naproxen and carbamazepine in aqueous solution onto natural clay: equilibrium, kinetics, and thermodynamic study
}

\author{
Hassen Khazri $^{1,2} \cdot$ Ibtissem Ghorbel-Abid $^{1,2} \cdot$ Rafik Kalfat $^{1} \cdot$ Malika Trabelsi-Ayadi $^{2}$
}

Received: 8 January 2016/Accepted: 4 April 2016/Published online: 21 April 2016

(c) The Author(s) 2016. This article is published with open access at Springerlink.com

\begin{abstract}
This study aimed to describe the adsorption of three pharmaceuticals compounds (ibuprofen, naproxen and carbamazepine) onto natural clay on the basis of equilibrium parameters such as a function of time, effect of $\mathrm{pH}$, varying of the concentration and the temperature. Adsorption kinetic data were modeled using the Lagergren's first-order and the pseudo-second-order kinetic equations. The kinetic results of adsorption are described better using the pseudo-second order model. The isotherm results were tested in the Langmuir, Freundlich and Dubinin-Radushkevich models. The thermodynamic parameters obtained indicate that the adsorption of pharmaceuticals on the clay is a spontaneous and endothermic process.
\end{abstract}

Keywords Drugs · Clay · Characterization · Adsorption · Kinetics · Isotherms · Thermodynamics

\section{Introduction}

The adverse effects of pharmaceutical residues in the aquatic environment have become an issue for the whole world (Margot et al. 2013; Halling-Sorensen et al. 1998).

Hassen Khazri

khazrihassen12@gmail.com

1 Laboratoire Matériaux, Traitement et Analyse, Institut National de Recherche et d'Analyse Physico-chimique, BiotechPole Sidi-Thabet, 2020 Ariana, Tunisia

2 Laboratory of Application Chemistry To the Resources and Natural Substances and the Environment (LACReSNE), Faculty of Science of Bizerte, 7021 Zarzouna, Bizerte, Tunisia
Presence of pharmaceutical residues in wastewater and surface water has been proven for many years by several studies (Bercu et al. 2008; Cunningham et al. 2009; Jones et al. 2004; Heberer 2002; Nanaki and Kyzas 2015). They are detected at low concentrations, ranging from $\mu \mathrm{g} \mathrm{L}^{-1}$ to $\mathrm{ng} \mathrm{L^{-1 }}$. Even though that these concentrations are very low and are difficult to detect, they have adverse impact on human health and environmental (Daughton and Ternes 1999). Elimination rate of the pharmaceutical substances varies according to the process employed; such as activated carbon filtration, UV treatment followed by biological treatment. Moreover, adsorption clay offers a large cation exchange capacity, high specific surface area and a significant swelling (Chen et al. 2008). The objective of this work is to make a contribution in the field of treatment of water by testing adsorption of three molecules (NAP, IBU, CBZ) onto clay mixture smectite and kaolinite, on base of different parameters to evaluate the adsorption performance, the kinetics of the adsorbent and the adsorption isotherms were studied to comprehend the adsorption processes.

\section{Materials and method}

\section{Presentation of materials}

Natural clay (CB) was collected from Jbel Sejnane (north east of Tunisia) and purified by mixing the clay frequently with $\mathrm{NaCl}$ solution to obtain a homo-ionic Na-clay noted (CP) (Chen et al. 2008). This step was performed by shaking $4 \mathrm{~g}$ of clay with $120 \mathrm{~cm}^{3}$ of a $\mathrm{NaCl}(1 \mathrm{M})$, then centrifuging the suspensions (Lopez-Ramon et al. 1999).

This process was repeated seven times. The Na-clay was then washed many times with distilled water. This cleaning was stopped when the $\mathrm{AgNO}_{3}$ test for chloride ions was 
negative. After drying at $60{ }^{\circ} \mathrm{C}$, the clay was crushed and sieved through less than $100 \mu \mathrm{m}$ to get of the very fine particles $(<2 \mu \mathrm{m})$. The specific surface area (Ss) and cation exchange capacity (CEC) were measured by the BET and Metson methods, respectively (AFNOR NF X 31e130).

The $\mathrm{pH}$ of the point of zero charge (pZC) has been determined according to a method previously described in the literature (Lopez-Ramon et al. 1999), $50 \mathrm{~mL}$ of a $0.01 \mathrm{M} \mathrm{NaCl}$ solution was first placed in a series of amber vials. The $\mathrm{pH}$ was then adjusted to successive initial values between 2 and 12, by adding either $\mathrm{HCl}$ or $\mathrm{NaOH}$ and the clay $(0.15 \mathrm{~g})$ was added to the solution. The final $\mathrm{pH}$, reached after $48 \mathrm{~h}$, is measured and plotted against the initial $\mathrm{pH}$. The $\mathrm{pH}$ at which the curve crosses the line $\mathrm{pH}$ (final) $=\mathrm{pH}$ (initial) is taken as the $\mathrm{pH}$ of the given adsorbent.

Three pharmaceuticals were selected in this research as target compounds: carbamazepine (an antiepileptic), ibuprofen and naproxen (analgesics), the molecular structure and physicochemical properties of these pharmaceuticals are summarized in Table 1.

Ibuprofen, naproxen and carbamazepine solutions with different concentrations were prepared by diluting the stock solution in ultra-pure water. NAP, IBU and CBZ concentrations were determined using the absorbance (at 230, 220 and $271 \mathrm{~nm}$, respectively) of the solutions using the UV spectra of the solution by a spectrophotometer (model of SP-3000 Plus).

The X-Ray diffraction pattern of the clay was recorded by X'Pert PRO MPD working on monochromatic radiation Copper $\mathrm{K}_{\alpha 1}(1.5406 \AA$ ). A counter (PM 8203) records a signal proportional to the intensity of the diffracted beam. The chemical composition of clay is performed by spectroscopy of emission out of gun plasma ICP PERKIN ELMER 3300. The spectroscopic studies were performed using a scanning electron microscopy (SEM, JSM.6300).

\section{Adsorption experiments}

All the adsorption experiments were carried out at $(298 \pm 0.2 \mathrm{~K})$, by batch adsorption. Stock solutions of pharmaceuticals were prepared as $50 \mathrm{mg} \mathrm{L}^{-1}$ by dissolution in ultrapure water. Individual batch adsorption experiments were carried out by shaking $25 \mathrm{mg}$ of clay with $25 \mathrm{~mL}$ of pharmaceuticals solution in a series of reagent flasks at a constant speed $(250 \mathrm{rpm})$ in a mechanical shaker for $6 \mathrm{~h}$ and centrifuged at $4000 \mathrm{rpm}$ after the samples were separated with the aid of a syringe nylon microfilter $(0.45 \mu \mathrm{m})$, and the concentration of each solution was measured by spectrophotometer at the corresponding wavelength. The $\mathrm{pH}$ of pharmaceuticals solution was adjusted with $(0.1 \mathrm{M}) \mathrm{HCl}$ or $(0.1 \mathrm{M}) \mathrm{NaOH}$.

Table 1 Molecular structure and main physicochemical properties of studied pharmaceuticals

\begin{tabular}{|c|c|c|c|}
\hline Drug/CAS number & Molecular structure & Molecular weight & $\mathrm{pKa}$ \\
\hline Naproxen/22204-53-1 & & 230.27 & 4.2 (Leite et al. 2008) \\
\hline Carbamazepine/298-46-4 & & 236.28 & 13.9 (Yaneva and Koumanova 2006) \\
\hline Ibuprofen/15687-27-1 & & 206.28 & 4.96 (Yaneva and Koumanova 2006) \\
\hline
\end{tabular}




\section{Adsorption isotherm}

To identify the mechanism of the adsorption process, the adsorption isotherm values were evaluated and analyzed. Different isotherm models are available in the literature. Simple, reliable, and widely used models, such as linear, Langmuir, and Freundlich isotherms, were used in this present study. The chosen isotherm models were applied to establish the relationship between the amount of pharmaceuticals adsorbed by the clay and its equilibrium concentration in the aqueous solution. The equilibrium studies were carried out using $25 \mathrm{mg}$ of clay in $25 \mathrm{~mL}$ of pharmaceuticals aqueous at different concentrations. The sorption capacity of the clay was evaluated by the amount of pharmaceuticals aqueous adsorbed using the following expression:

$Q=\frac{\left(C_{0}-C_{\mathrm{e}}\right) \times V}{M}$

where, $Q$ is the amount of solute retained per mass unit of the adsorbent $\left(\mathrm{mg} \mathrm{g}^{-1}\right), C_{0}$ and $C_{\mathrm{e}}$ are the initial and equilibrium concentration of pharmaceuticals in the solution $\left(\mathrm{mg} \mathrm{L}^{-1}\right)$.

$M$ is the amount of sorbent $(\mathrm{g})$, and $V$ is the volume of the solution $(\mathrm{L})$.

The percentage of the pharmaceuticals was evaluated as follows:

$R(\%)=\frac{\left(C_{0}-C_{\mathrm{e}}\right) \times 100}{C_{0}}$

The Langmuir model assumes that the adsorbent surface is homogeneous and contains only one type of binding site, so the energy of adsorption is constant, which is presented by the following equation:

$Q_{e}=\frac{K_{L} \cdot Q_{e} \cdot C_{e}}{\left(1+\left(K_{L} \cdot C_{e}\right)\right)}$

The linear form of Langmuir adsorption isotherm can be expressed as follows:

$\frac{C_{\mathrm{e}}}{Q_{\mathrm{e}}}=\frac{1}{Q_{0} \cdot K_{\mathrm{L}}}+\frac{1}{Q_{0}} \cdot C_{\mathrm{e}}$

where $Q_{0}\left(\mathrm{mg} \mathrm{g}^{-1}\right)$ is the Langmuir constant related to the maximum monolayer adsorption capacity and $K_{\mathrm{L}}\left(\mathrm{L} \mathrm{mg}^{-1}\right)$ is the constant related to the free energy or net enthalpy of the adsorption (Angove et al. 1997).

The Freundlich model can be applied for multilayer adsorption on a heterogeneous adsorbent surface, with sites that have different energies of adsorption. The Freundlich model is given by the following equation (Freundlich 1906).

$Q_{\mathrm{e}}=K_{\mathrm{F}} \cdot\left(C_{\mathrm{e}}^{\frac{1}{n}}\right)$

This expression can be linearized to give the following equation:
$\operatorname{Ln} Q_{\mathrm{e}}=\operatorname{Ln} K_{\mathrm{F}}+\frac{1}{n} \cdot \operatorname{Ln} C_{\mathrm{e}}$

where " $K_{\mathrm{F}}$ " $\left(\mathrm{mg} \mathrm{g}^{-1}\right)$ and " $n$ " are Freundlich constants related to adsorption capacity and intensity, respectively.

Dubinin-Radushkevich (DR) isotherm has been used to describe the sorption of drugs onto clay and helps in understanding the type of adsorption (Donat et al. 2005; Hosseini et al. 2003). DR equation can be written as Eq. (7).

The DR equation has the following form

$\ln q_{\mathrm{e}}=\ln q_{\mathrm{s}}-k \varepsilon^{2}$

where $q_{\mathrm{e}}$ is DR monolayer capacity $\left(\mathrm{mg} \mathrm{g}^{-1}\right), k$ is a constant related to adsorption energy; $q_{\mathrm{s}}$ is the amount of drugs adsorbed per unit weight of adsorbent $\left(\mathrm{mg} \mathrm{g}^{-1}\right)$ and $\varepsilon$ is the Polanyi potential, which can be expressed as:

$\varepsilon=\mathrm{RT} \ln \left(1+\frac{1}{C_{\mathrm{e}}}\right)$

where $C_{\mathrm{e}}$ is the equilibrium concentration of drug in aqueous solution ( $\left.\mathrm{mg} \mathrm{L}^{-1}\right), R$ is the gas constant and $T$ is the temperature $(\mathrm{K})$, the slope of the line makes it possible to calculate the value of $k$ and the intercept gives the adsorption capacity, $q_{\mathrm{m}}$.

\section{Adsorption kinetics}

Kinetic models are helpful in understanding the mechanism of molecule adsorption and in evaluating the performance of the adsorbents. A number of kinetic models have been developed to describe the kinetics of heavy molecule adsorption. In this present study, the kinetic of pharmaceuticals adsorption on the clay were determined with different kinetic models such as the first-order and the pseudo-second order models.

The period of time necessary to reach the equilibrium, previous kinetic experiments were performed. Fixed amounts of adsorbent $(25 \mathrm{mg})$ and volumes of adsorptive solution $(25 \mathrm{~mL})$ of initial concentration equal to (50 $\mathrm{mg} \mathrm{L}^{-1}$ ) were kept in contact under shaking $(250 \mathrm{rpm})$ and at constant temperature $(T=298 \pm 0.2 \mathrm{~K})$ for different preset time intervals [0-360 min]. Whenever varies in time we take a sample and make it past the centrifuge.

Finally, the supernatant was analyzed by the spectrometer.

The first-order rate equation of the Lagergren is one of the most widely used kinetic models for the adsorption of a solute from a solution (Lagergren 1898). The model has the following form:

$\frac{\mathrm{dQ}}{\mathrm{d} t}=K_{1}\left(Q_{\mathrm{e}}-Q_{t}\right)$

where $Q_{\mathrm{e}}\left(\mathrm{mg} \mathrm{g}^{-1}\right)$ is the amount of the metal ions adsorbed on the adsorbent at equilibrium, and $K_{1}\left(\mathrm{~min}^{-1}\right)$ is the rate constant of the first-order adsorption. After 
integration and application of boundary conditions $Q_{t}=0$ at $t=0$ and $Q_{t}=Q_{t}$ at $t=t$, the integral form of Eq. (8) becomes the following:

$\operatorname{Ln}\left(Q_{\mathrm{e}}-Q_{t}\right)=\ln Q_{\mathrm{e}}-K_{1} \cdot t$

The second-order kinetic model, on the basis of the adsorption equilibrium capacity, is as follows (Hosseini et al. 2003).

$\frac{\mathrm{dQ}}{\mathrm{d} t}=K_{2}\left(Q_{\mathrm{e}}-Q_{t}\right)^{2}$

where $K_{2}\left(\mathrm{~g} \mathrm{mg}^{-1} \mathrm{~min}^{-1}\right)$ is the rate constant of the second-order equation and $Q\left(\mathrm{mg} \mathrm{g}^{-1}\right)$ is the maximum dye adsorbed. After definite integration through the application of boundary conditions $Q_{t}=0$ at $t=0$ and $Q_{t}=Q_{t}$ at $t=t$, Eq. (10) becomes the following:

$\frac{t}{Q_{t}}=\frac{1}{2\left(Q_{\mathrm{e}}^{2} \cdot K_{2}\right)}+\frac{t}{Q_{\mathrm{e}}}$

If the second-order kinetic model is applicable, then the plot of $\frac{t}{Q_{\mathrm{e}}}$ versus $t$ should give a straight line, and $Q_{\mathrm{e}}$ and $K_{2}$ could be obtained from the slope and intercept of the straight line, respectively.

\section{Sorption thermodynamics}

Thermodynamic parameters, including changes in the free energy $\left(\Delta G^{\circ}\right)$, enthalpy $\left(\Delta H^{\circ}\right)$, and entropy $\left(\Delta S^{\circ}\right)$ associated with the adsorption process, can be determined using the following equations (Ho and McKay 1998; Moore and Reynolds 1997).

$\Delta G^{\circ}=-\mathrm{RT} \ln K_{\mathrm{c}}$

$\Delta G^{\circ}=\Delta H^{\circ}-T \Delta S^{\circ}$

The plot of $\operatorname{Ln} K_{\mathrm{c}}$, as a function of $\frac{1}{T}$, yields a straight line, from which $\Delta H^{\circ}$ and $\Delta S^{\circ}$ can be calculated from the slope and intercept, respectively.

\section{Results and discussion}

\section{Characteristics of the clay}

Chemical compositions in weight percentage for the raw material denoted as $\mathrm{CB}$, and for the Na-purified clay denoted as CP are given in Table 2.

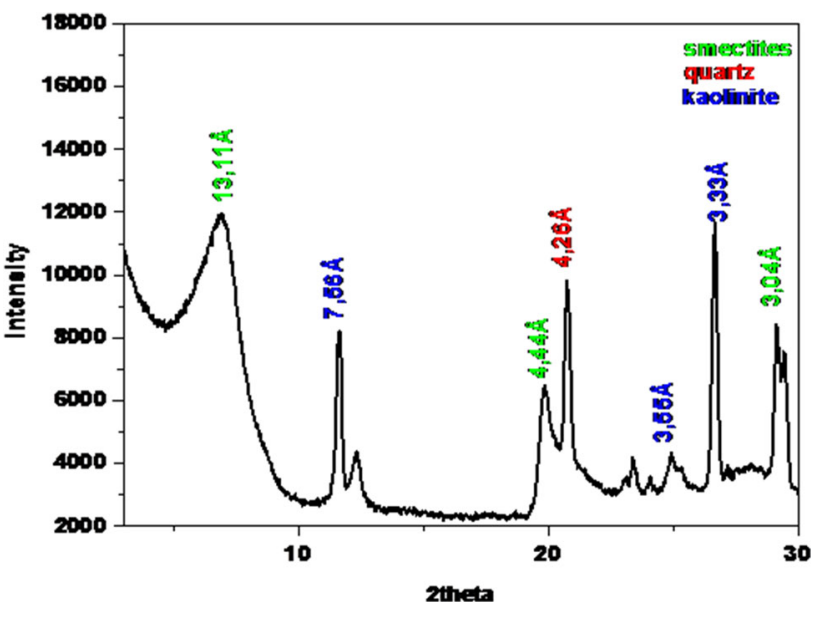

Fig. 1 XRD powder of Na-purified clay (CP)

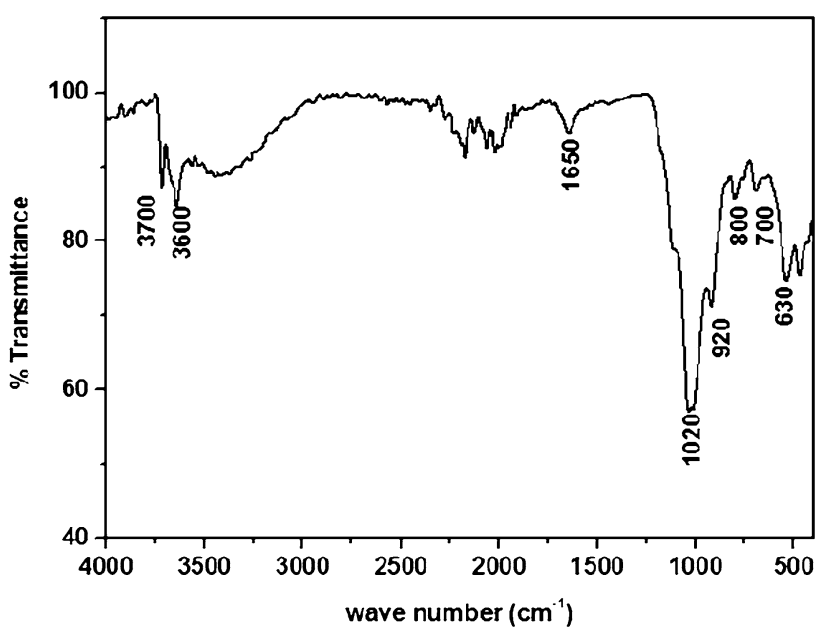

Fig. 2 FT-IR spectra of Na-purified clay (CP)

The CEC and SSA for the Na-purified dried clay fraction are $46 \mathrm{meq} / 100 \mathrm{~g}, 69.5 \mathrm{~m}^{2} \mathrm{~g}^{-1}$.

The X-ray diffraction (XRD) of the clay is shown in Fig. 1. The clay contains a mixture of quartz and kaolinitesmectite. Figure 2 shows the FT-IR spectrum of the clay. An intense band located at $1020 \mathrm{~cm}^{-1}$, this band is characteristic of the $\mathrm{Si}-\mathrm{O}$ stretching vibration of cristobalite. The band at $3700 \mathrm{~cm}^{-1}$ corresponds to the stretching vibration of the hydroxyl groups located between the tetrahedral and octahedral layers of the clay (Leite et al. 2008). The absorption located at $3600 \mathrm{~cm}^{-1}$ and the band

Table 2 Chemical composition of Jebel Sejnane clay

\begin{tabular}{|c|c|c|c|c|c|c|c|c|c|c|c|c|c|c|}
\hline & & $\mathrm{SiO}_{2}$ & $\mathrm{Al}_{2} \mathrm{O}_{3}$ & $\mathrm{CaO}$ & $\mathrm{MgO}$ & $\mathrm{Na}_{2} \mathrm{O}$ & $\mathrm{K}_{2} \mathrm{O}$ & $\mathrm{P}_{2} \mathrm{O}_{5}$ & $\mathrm{FeO}_{3}$ & $\mathrm{MnO}$ & $\mathrm{ZnO}$ & $\mathrm{CuO}$ & Total & $\mathrm{PF}$ \\
\hline \multirow[t]{2}{*}{ wt $(\%)$} & $\mathrm{CB}$ & 62.02 & 8.37 & 0.84 & 2.61 & 0.52 & 0.74 & 0.14 & 13.24 & 0.01 & 0.01 & 0.03 & 88.57 & 11.04 \\
\hline & $\mathrm{CP}$ & 60.45 & 11.70 & 0.64 & 2.83 & 0.71 & 2.74 & 0.03 & 8.32 & 0.01 & 0.03 & 0 & 87.49 & 12.50 \\
\hline
\end{tabular}


Fig. 3 SEM images of clay and clay after adsorption of pharmaceuticals
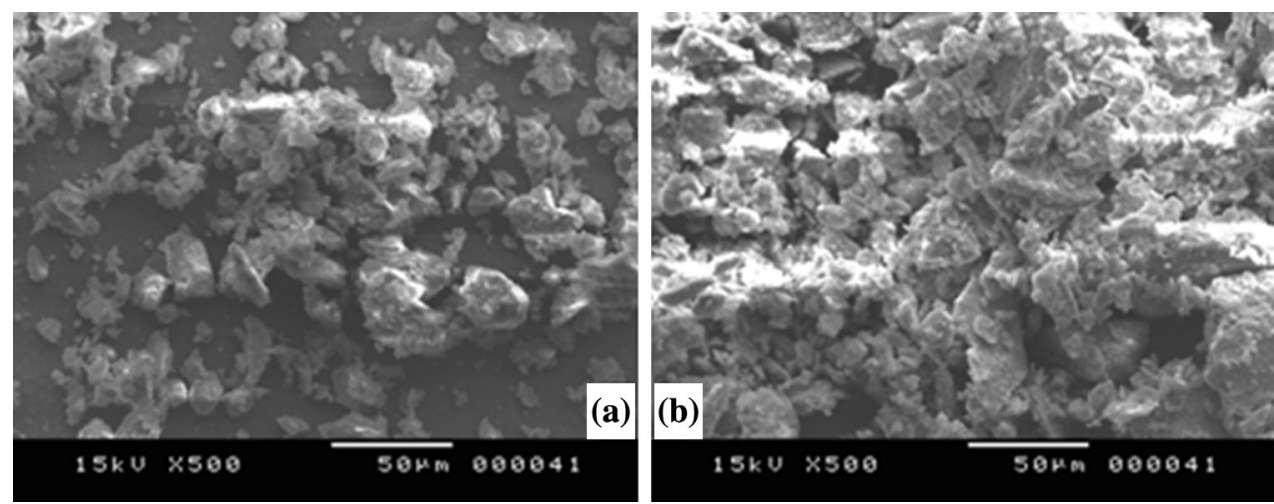

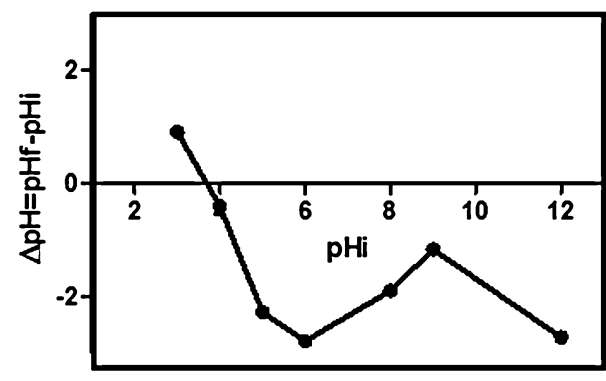

Fig. 4 Zeta potential of clay

near $1650 \mathrm{~cm}^{-1}$ is due to the presence of water molecules adsorbed on the clay structure (Madejova and Komadel 2001). The band at $790 \mathrm{~cm}^{-1}$ may be evidence for the presence of silica and quartz. Other bands located at 920 and $530 \mathrm{~cm}^{-1}$ correspond to deformations of $\mathrm{Al}-\mathrm{Al}-\mathrm{OH}$ and $\mathrm{Al}-\mathrm{O}-\mathrm{Si}$, respectively (Yaneva and Koumanova 2006). SEM photographs show the textural structural examination of clay before and after the adsorption Fig. 3.

In Fig. 3a, clay showed a non-homogeneous surface. Also, the surface change in the SEM photograph of the clay after adsorption of drugs indicates the structural changes in the sorbent which is depicted in Fig. $3 b$.

The point of zero charge (pZC) of the clay used in this study presented in Fig. 4. The clay was observed to possess a point of zero charge $(\mathrm{pZC})$ at a $\mathrm{pH}_{(\mathrm{pZC})}=3.78$, so its surface has a high affinity for cations at $\mathrm{pHs}$ above this value. The surface of the clay was neutral at $\mathrm{pH}=3.78$.

\section{Effect of contact time}

Figure 5 shows pharmaceuticals removal at different contact times using clay as an adsorbent. Pharmaceutical removal increased rather rapidly with the increase of contact time, but then gradually approached a more or less constant value denoting the attainment of equilibrium. The fast kinetics of adsorption during the first minutes of the reaction can be interpreted by the fact that at the beginning of adsorption the number of available active sites on the

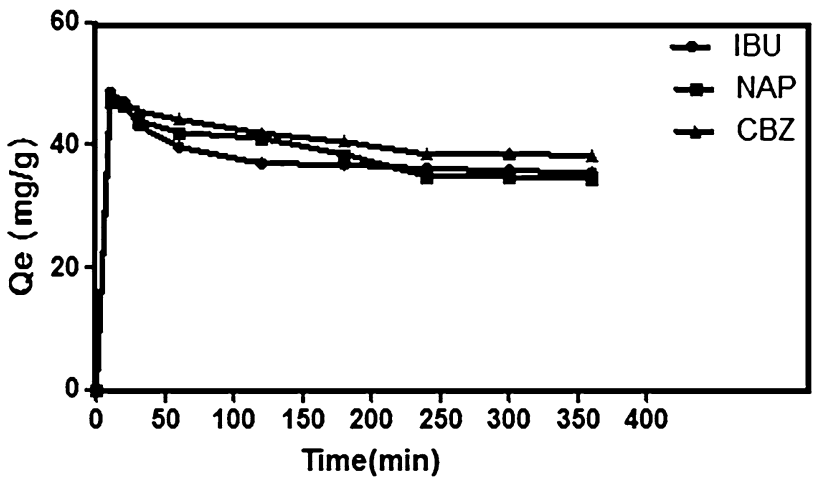

Fig. 5 Effect of contact time on the adsorption of pharmaceuticals onto the clay $\left(T=298.0 \pm 0.2^{\circ} \mathrm{K}, \mathrm{pH}=6\right)$

surface of the adsorbent material is much greater than that remaining after sites a certain time (Stipp 1999). In addition a chemical interaction diffusion and other driving forces can occurred. Besides, the sorption rate decreased due to less sorption as a result of the migration of pharmaceutical cation layer to the interior pore/capillary surfaces. After $240 \mathrm{~min}$, the rate of removal of pharmaceuticals is constant indicate the equilibrium and the non-availability of sorption sites. The maximum adsorption of drugs onto clay was observed at $240 \mathrm{~min}$ for CBZ, $240 \mathrm{~min}$ for NAP and $180 \mathrm{~min}$ for IBU.

\section{Modeling of adsorption isotherm}

The kinetic models for adsorption are useful for clarifying the mechanism of adsorption (see Figs. 6, 7).

The adsorption kinetics of three drugs on clay were investigated using the first-order kinetics and the pseudosecond-order kinetics

According to the results of the correlation coefficients $(R)$ shown in Table 3, we note that the pseudo-second order model is the most reliable way to determine the order of adsorption kinetics for all pharmaceuticals by clay. Furthermore, The values of $Q_{\text {cal }}$ calculated by the pseudo-second order model in Table 3; are close to that 


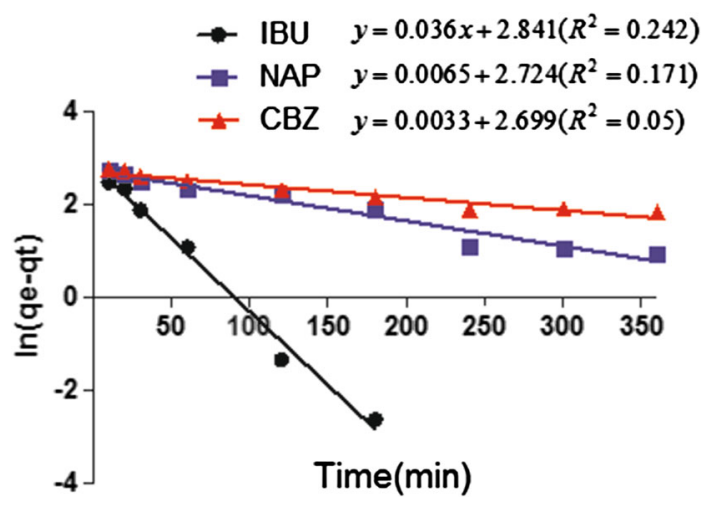

Fig. 6 First-order model equation of pharmaceuticals adsorption

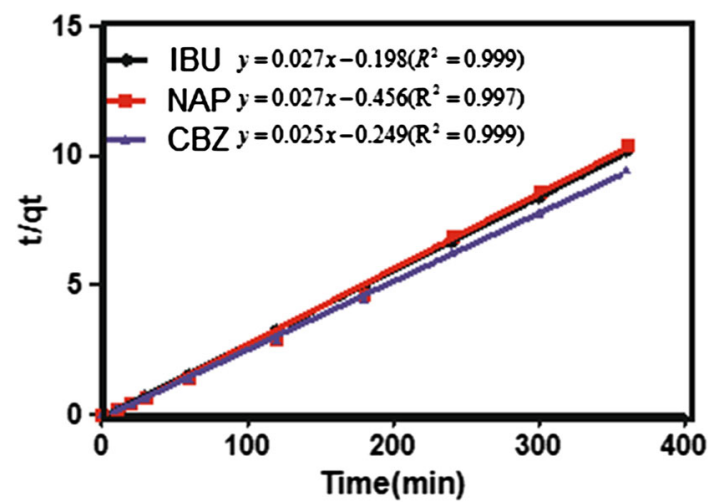

Fig. 7 Pseudo-second order model equation for pharmaceuticals adsorption

determined experimentally, which confirms that the adsorption kinetics of the drug onto clay are pseudosecond order.

\section{Adsorption isotherms}

The objective of the isotherms has been used as the better method in the study of the theoretical aspects of adsorption. The result in Fig. 8 show the influence of the concentration in the ability of pharmaceuticals amount adsorbed which increases with the rise of equilibrium concentration (see Table 4).
The amount of adsorbed naproxen and ibuprofen onto clay is higher than that of carbamazepine, as can be seen, the adsorption efficacy ranking is as follows: naproxen $\left(Q_{\mathrm{e}}=37 \mathrm{mg} \mathrm{g}^{-1}\right)>$ ibuprofen $\quad\left(Q_{\mathrm{e}}=36 \mathrm{mg} \mathrm{g}^{-1}\right)>$ carbamazepine $\left(Q_{\mathrm{e}}=32 \mathrm{mg} \mathrm{g}^{-1}\right)$. This could be due to $(\mathrm{pH}=6)$ carbamazepine is in its neutral form; naproxen and ibuprofen are both protonated. In addition, the surface of the clay is negatively charged, it is reasonable that naproxen-ibuprofen will be absorbed more important than the carbamazepine. According to Fig. 8, we observe that the adsorption isotherms of three pharmaceutical molecules (NAP, IBU, CBZ) onto clay have the same look: the quantity of drugs increases for low concentrations in solution and then attenuated to achieve forme plate corresponding to a saturation of adsorption sites.

The shape of the isotherm pharmaceuticals at $\mathrm{pH}=6$ is S-type (Cuerda-Correa et al. (2010). Indeed, the isotherms of this class have a concavity facing upward at a low concentration; the adsorbed molecules promote the subsequent adsorption of other molecules. This is due to the interactions between the molecules which are attracted to van der Waals forces.

\section{Sorbent isotherms}

Constants of isotherms are commonly used in describing the adsorption equilibrium from aqueous solutions.

The experimental equilibrium data were modeled using the Freundlich model, the Langmuir model and DubininRadushkevich (DR) isotherm model to quantify the adsorption capacity of the adsorbent for the removal of pharmaceuticals.

Figures 9 and 10 show the Freundlich and Langmuir equation obtained by the adsorption of pharmaceuticals onto clay.

Figure 11 shown the $\ln q_{\mathrm{e}}$ against $\varepsilon^{2}$; the slopes of the line makes it possible to calculate the value of $k$ and the intercept gives the adsorption capacity, $q_{\mathrm{m}}$.

The isotherm results obtained for Langmuir, Freundlich and Dubinin-Radushkevich (DR) models are presented in Table 5; On the basis of the correlation coefficient values $\left(R^{2}\right)$, the Freundlich model is the most reliable for the

Table 3 Kinetic parameters for the adsorption of pharmaceuticals onto clay

\begin{tabular}{|c|c|c|c|c|c|c|c|c|}
\hline \multicolumn{6}{|c|}{ First order parameters } & \multicolumn{3}{|c|}{ Pseudo-second order rate parameters } \\
\hline PPs & Sorbent & $Q_{\exp }\left(\mathrm{mg} \mathrm{g}^{-1}\right)$ & $Q_{\text {cal }}\left(\mathrm{mg} \mathrm{g}^{-1}\right)$ & $k_{1}\left(\min ^{-1}\right)$ & $R^{2}$ & $Q_{\mathrm{cal}}\left(\mathrm{mg} \mathrm{g}^{-1}\right)$ & $k_{2}\left(\mathrm{~g} \mathrm{mg}^{-1} \min ^{-1}\right)$ & $R^{2}$ \\
\hline IBU & Clay & 37 & 1.0030 & 0.0360 & 0.242 & 37 & 0.0018 & 0.999 \\
\hline NAP & & 37 & 1 & 0.0060 & 0.171 & 37 & 0.0008 & 0.997 \\
\hline CBZ & & 32 & 1 & 0.0030 & 0.050 & 40 & 0.0012 & 0.999 \\
\hline
\end{tabular}




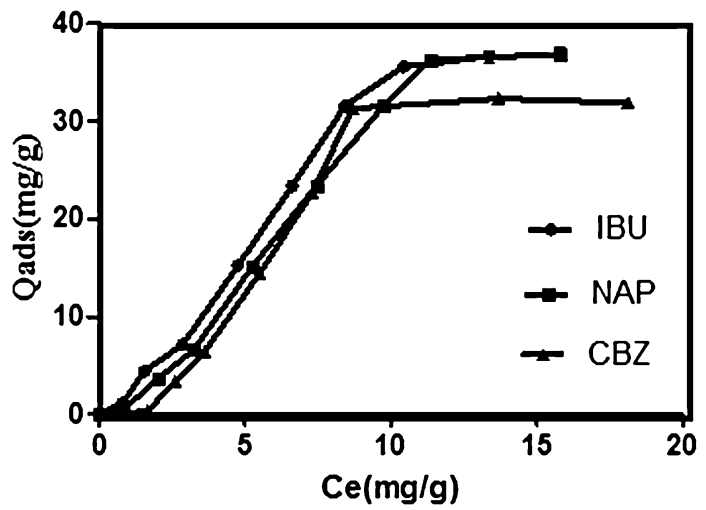

Fig. 8 Adsorption isotherm on pharmaceuticals onto clay $(\mathrm{pH}=6$, $\left.T=298.0 \pm 0.2^{\circ} \mathrm{K}\right)$

Table 4 Isotherm parameters obtained by fitting equilibrium data with the Langmuir, Freundlich and Dubinin - Radushkevich isotherms for the adsorption of pharmaceuticals on clay

\begin{tabular}{|c|c|c|c|}
\hline & IBU & NAP & $\mathrm{CBZ}$ \\
\hline \multicolumn{4}{|c|}{ Langmuir parameters } \\
\hline$Q_{\mathrm{e}}\left(\mathrm{mg} \mathrm{g}^{-1}\right)$ & 3.52 & 2.87 & 3.40 \\
\hline$K_{\mathrm{L}}\left(\mathrm{mg} \mathrm{L}^{-1}\right)$ & 1.37 & 0.43 & 1.46 \\
\hline$R^{2}$ & 0.90 & 0.91 & 0.93 \\
\hline \multicolumn{4}{|c|}{ Freundlich parameters } \\
\hline$K_{\mathrm{f}}\left(\mathrm{mg} \mathrm{g}^{-1}\right)$ & 1.35 & 1.68 & 1 \\
\hline $\mathrm{nf}$ & 0.85 & 0.52 & 0.64 \\
\hline$R^{2}$ & 0.98 & 0.97 & 0.98 \\
\hline \multicolumn{4}{|c|}{ Linear form of DR } \\
\hline$Q_{\mathrm{e}}\left(\mathrm{mg} \mathrm{g}^{-1}\right)$ & 50 & 30.87 & 31.18 \\
\hline$K$ & $8.19 \times 10^{-7}$ & $2.60 \times 10^{-7}$ & $1.70 \times 10^{-6}$ \\
\hline$E$ & 0.78 & 0.43 & 0.54 \\
\hline$R^{2}$ & 0.86 & 0.92 & 0.92 \\
\hline
\end{tabular}

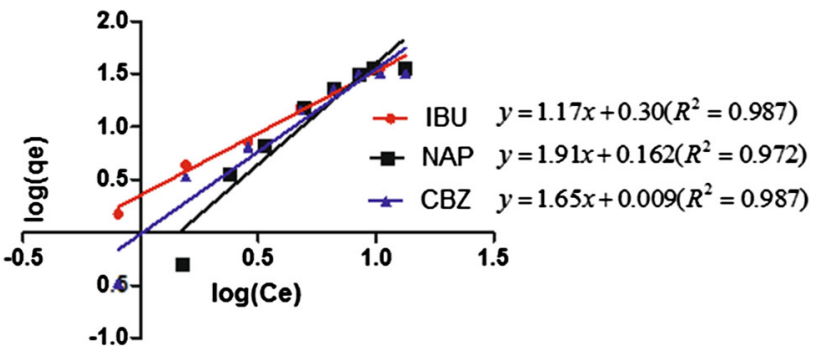

Fig. 9 Freundlich model for the adsorption of pharmaceuticals onto clay

description of the isotherms adsorption than their Langmuir model.

The (DR) isotherm is more general than the Langmuir and Freundlich isotherm, it was studied to differentiate between the chemical and physical adsorption.

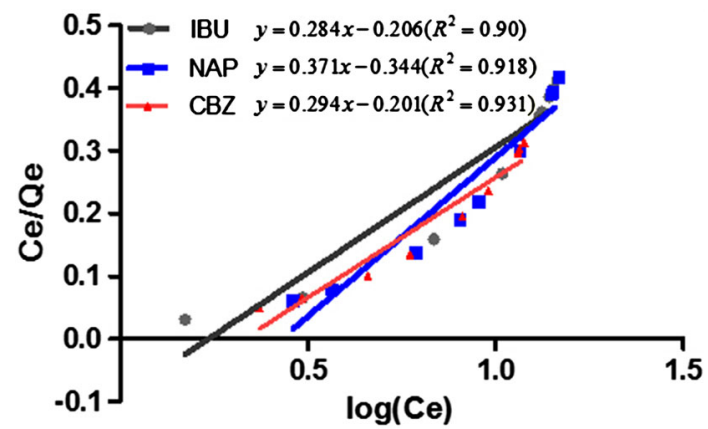

Fig. 10 Langmuir model for the adsorption of pharmaceuticals onto clay

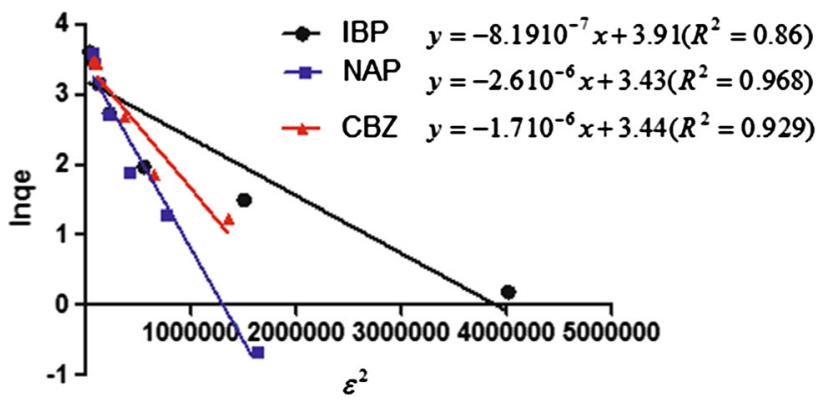

Fig. 11 Dubinin-Radushkevich model for the adsorption of pharmaceuticals onto clay

Table 5 Experimental results of thermodynamics of adsorption of pharmaceuticals

\begin{tabular}{lllll}
\hline$T(\mathrm{~K})$ & $K_{\mathrm{c}}$ & $\Delta H^{\circ}\left(\mathrm{kJ} \mathrm{mol}^{-1}\right)$ & $\Delta S^{\circ}\left(\mathrm{kJ} \mathrm{mol}^{-1} \mathrm{~K}^{-1}\right)$ & $\Delta G^{\circ}\left(\mathrm{J} \mathrm{mol}^{-1}\right)$ \\
\hline 293 & 1 & 10.50 & 0.03 & -7.29 \\
313 & 1.14 & & & -340.79 \\
333 & 1.67 & & & -1433.95 \\
293 & 1.00 & 11.05 & 0.03 & -12.14 \\
313 & 1.30 & & & -692.73 \\
333 & 2.22 & & & -2212.93 \\
293 & 1 & 8.01 & 0.02 & -9.72 \\
313 & 1 & & & -283.26 \\
333 & 1.48 & & & -1102.17 \\
\hline
\end{tabular}

The constant $\mathrm{k}$ is used to calculate the mean free energy $E\left(\mathrm{~kJ} \mathrm{~mol}^{-1}\right)$ defined as the free energy change when $1 \mathrm{~mol}$ of ion is transferred to the surface of the solid from infinity in solution (Polanyi 1932; Bering et al. 1972). The equation can be given as follows:

$E=(2 k)^{\left(-\frac{1}{2}\right)}$

For drugs sorption onto clay, the mean free energy values obtained in this work (Table 5) are $0.78 \mathrm{~kJ} \mathrm{~mol}^{-1}$ of ibuprofen, $0.43 \mathrm{~kJ} \mathrm{~mol}^{-1}$ of naproxen and $0.54 \mathrm{~kJ} \mathrm{~mol}^{-1}$ of 


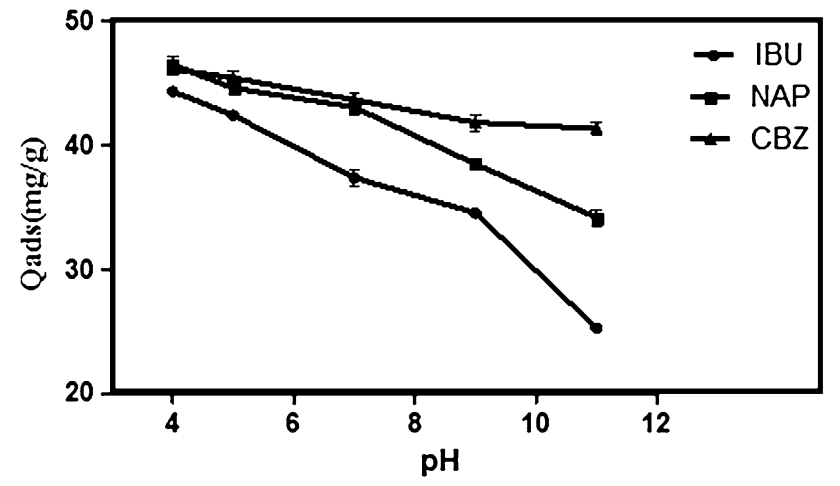

Fig. 12 Effect of $\mathrm{pH}$ on the removal of pharmaceuticals onto clay, $\left(C_{i}=50 \mathrm{mg} \mathrm{L}^{-1}, T=298.0 \pm 0.2^{\circ} \mathrm{K}\right)$

carbamazepine at $298^{\circ} \mathrm{K}$. This parameter gives information concerning the nature of adsorption, while the values energy for an ion-exchange mechanism is $8-16 \mathrm{~kJ} \mathrm{~mol}^{-1}$ (Ho et al. 2001), therefore the adsorption process of three drugs into clay is controlled by physical adsorption.

\section{Effect of pH}

Figure 12 shows the effect of $\mathrm{pH}$ on the removal of pharmaceuticals, into the clay at different $\mathrm{pH}$ values. Generally, the absorptions of pharmaceutical depend strongly on the pH of the solution (Rivera-Jiménez et al. 2010; Bui and Choi 2009).

From the figure, it may be concluded that the retention of drugs is remarkably influenced by the $\mathrm{pH}$. This parameter plays a very important role in the adsorption process, and particularly, in the adsorption capacity. When the $\mathrm{pH}$ increased from 4 to 11 , the removal of drugs reduced gradually.

The pKa of naproxen and ibuprofen are 4.2 and 4.96, respectively. For basic $\mathrm{pH}$ values, the dissociation degree of the surface groups of the adsorbent as well as that of the chemicals is high, so the adsorbent and the solutes occur in their negatively charged forms.

The adsorption of pharmaceuticals onto clay can be leading to an electrostatic repulsion between them. This implies that the adsorption is disfavored. In the case of carbamazepine, it's a neutral compound in the $\mathrm{pH}$ tested range; its binding onto clay is solely attributable to a non electrostatic interaction involving the hydrogen bonding probably through the oxygen groups of esters-and van der Waals interactions (Turku et al. 2007).

\section{Effect of temperature}

Figure 13 depicts the adsorption isotherms of naproxen, ibuprofen and carbamazepine at different temperatures. The adsorption isotherms shown in Fig. 13 indicate clearly

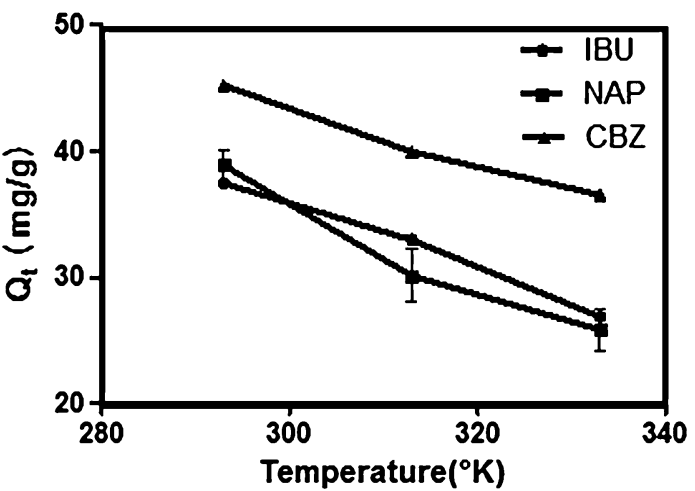

Fig. 13 Effect of temperature on the adsorption of pharmaceuticals onto clay $\left(C_{i}=50 \mathrm{mg} \mathrm{L}^{-1}, \mathrm{pH}=6\right)$

that the increase of the temperature affects negatively at the adsorption process. Besides, as temperature rises, the adsorption capacity decreases markedly. We noticed that the increase of temperature from 298 to $333 \mathrm{~K}$ induces a decrease of the adsorption capacity. The rise of temperature ensures the destabilization of the physical forces involved, so we concluded that there is an optimum value of temperature to promote the adsorption of pharmaceuticals.

In general, the adsorption is always accompanied by a thermal process (Rytwo and Ruiz-Hitzky 2003; Ramesh et al. 2005) which may be either exothermic $\left(\Delta H^{\circ}<0\right)$ or endothermic $\left(\Delta H^{\circ}>0\right)$. Measuring the heat of adsorption $\Delta H^{\circ}$ is the main criterion that differentiates the chemisorption of physisorption.

The heat of adsorption $\Delta H^{\circ}$ is given by the GibbsHelmholtz relationship (El-Rahman et al. 2006; Demirbas et al. 2006):

$\Delta G^{\circ}=-\mathrm{RT} \ln K_{\mathrm{c}}$

$\Delta G^{\circ}=\Delta H^{\circ}-T \Delta S^{\circ}$

$\frac{(14)}{(15)} \operatorname{Ln} K_{\mathrm{c}}=\frac{\Delta S^{\circ}}{R}-\frac{\Delta H^{\circ}}{R \cdot T}$

With $: K_{\mathrm{c}}=\frac{C_{\mathrm{e}}}{M \cdot\left(C_{0}-C_{\mathrm{e}}\right)} \cdot V$

where: $K_{\mathrm{c}}$ equilibrium constant, $\Delta G^{\circ}$ Gibbs free energy $\left(\mathrm{J} \mathrm{mol}^{-1}\right), \Delta H^{\circ}$ enthalpy $\left(\mathrm{KJ} \mathrm{mol}^{-1}\right), \Delta S^{\circ}$ entropy $\left(\mathrm{KJ} \mathrm{mol}^{-1} \mathrm{~K}^{-1}\right), \quad T$ absolute temperature $(\mathrm{K}), \quad C_{\mathrm{o}}$ initial concentration of the adsorbate, $C_{\mathrm{e}}$ equilibrium concentration of the adsorbate, $V$ volume of solution, $m$ mass of the sorbent, $R$ gas constant $\left(8.314 \mathrm{~J} \mathrm{~mol}^{-1} \mathrm{~K}^{-1}\right)$.

The heat of adsorption $\Delta H^{\circ}$ and the entropy $\Delta S^{\circ}$ adsorption on clay was determined graphically by plotting $\mathrm{Ln} K_{\mathrm{c}}$ in function of the inverse of the temperature in Kelvin of the medium as shown in Fig. 14.

The positive value of $\Delta H^{\circ}\left(11.06 \mathrm{~kJ} \mathrm{~mol}^{-1}\right)$ confirms that the adsorption of adsorbate on the clay is an 


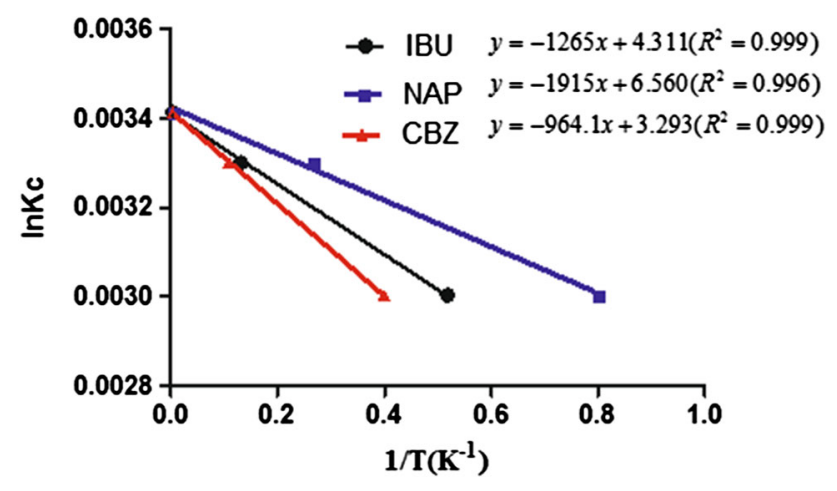

Fig. 14 Determination of the enthalpies and entropies of adsorption of pharmaceuticals onto clay

endothermic process. Also, the low values of this heat $\left(<40 \mathrm{~kJ} \mathrm{~mol}^{-1}\right)$ indicate that this is a physical adsorption. The positive value of $\Delta S^{\circ}\left(0.03 \mathrm{~kJ} \mathrm{~mol}^{-1} \mathrm{~K}^{-1}\right)$ corresponds to an increase in randomness at the solid solution interface with some structural changes in the adsorbate and adsorbent (Kyzas and Koltsakidou 2015). Also, some structural changes may have taken place as a result of interaction of molecule with active groups in the clay surface (Yadava et al. 1991).

The negative values of $\Delta G^{\circ}$ of drugs onto clay at different temperatures explain the spontaneous nature of the sorption process

\section{Conclusion}

This study indicates that the clay which contains a mixture of (smectite-kaolinite) and quartz could be used as an efficient low-cost adsorbent. Kinetic data of pharmaceuticals followed the pseudo-second-order kinetic model. Langmuir and Freundlich equations were used to describe the adsorption of drugs onto clay. The Freundlich equation is in good agreement with the experimental results. The adsorption isotherms pharmaceuticals of clay are satisfactorily described by the Freundlich model. The positive values of $\Delta H^{\circ}$ confirm the endothermic nature of the adsorption. The increasing values of $\Delta G^{\circ}$ with temperature show the spontaneity in the sorption processes pharmaceuticals reagent on clay.

Acknowledgments Thanks to National Institute of Research and Physico-chemical Analysis (INRAP) for supporting the analysis.

Open Access This article is distributed under the terms of the Creative Commons Attribution 4.0 International License (http:// creativecommons.org/licenses/by/4.0/), which permits unrestricted use, distribution, and reproduction in any medium, provided you give appropriate credit to the original author(s) and the source, provide a link to the Creative Commons license, and indicate if changes were made.

\section{References}

Angove MJ, Johnson BB, Wells JD (1997) The influence of temperature on the adsorption of cadmium (II) and cobalt(II) on kaolinite. Coll Surf A Phys Eng Aspects 126:137-147

Bercu JP, Parke NJ, Fiori JM, Meyerhoff RD (2008) Human health risk assessments for three neuropharmaceutical compounds in surface waters. Regul Toxicol Pharmacol 50(3):420-427

Bering BP, Dubinin MM, Serpenski VV (1972) On thermodynamics of adsorption on micropores. J Coll Interf Sci 38:185-194

Bui TX, Choi H (2009) Adsorptive removal of selected pharmaceuticals by mesoporous silica SBA-15. J Hazard Mater 168(2):602-608

Chen WJ, Hsiao LC, Chen KKY (2008) Metal desorption from copper (II)/nickel (II)-spiked kaolin as a soil component using plantderived saponin biosurfactant. Process Biochem 43(5):488-498

Cuerda-Correa EM, Domínguez-Vargas JR, Olivares-Marín FJ, de Heredia JB (2010) On the use of carbon blacks as potential lowcost adsorbents for the removal of non-steroidal anti-inflammatory drugs from river water. J Hazard Mater 177(1):1046-1053

Cunningham VL, Binks SP, Olson MJ (2009) Human health risk assessment from the presence of human pharmaceuticals in the aquatic environment. Regul Toxicol Pharmacol 53(1):39-45

Daughton CG, Ternes TA (1999) Pharmaceuticals and personal care products in the environment: agents of subtle change? Environ Health Perspect 107(Suppl 6):907

Demirbas A, Sari A, Isildak O (2006) Adsorption thermodynamics of stearic acid onto bentonite. J Hazard Mater 135(1):226-231

Donat R, Akdogan A, Erdem E, Etis Li HC (2005) Thermodynamics of $\mathrm{Pb}^{2+}$ and $\mathrm{Ni}^{2+}$ adsorption onto natural bentonite from aqueous solution. J Coll Interf Sci 286:43-52

El Messabeb-Ouali A, Benna-Zayani M, Kbir-Ariguib N, TrabelsiAyadi M (2008) Etude physico-chimique dune argile Tunisienne purifiée sodiquement échangée. Alger J Technol 4(1):123-135

El-Rahman KA, El-Kamash AM, El-Sourougy MR, Abdel-Moniem NM (2006) Thermodynamic modeling for the removal of $\mathrm{Cs}^{+}$, $\mathrm{Sr}^{2+}, \mathrm{Ca}^{2+}$ and $\mathrm{Mg}^{2+}$ ions from aqueous waste solutions using zeolite A. J Radioanal Nucl Chem 268(2):221-230

Freundlich MF (1906) Over the adsorption in solution. J Phys Chem 57(385):470

Halling-Sorensen B, Nors Nielsen S, Lanzky PF, Ingerslev F, Holten Lutzhoft HC, Jorgensen SE (1998) Occurrence, fate and effects of pharmaceutical substances in the environment-a review. Chemosphere 36:357-393

Heberer T (2002) Occurrence, fate, and removal of pharmaceutical residues in the aquatic environment: a review of recent research data. Toxicol Lett 131(1):5-17

Ho YS, McKay G (1998) A two-stage batch sorption optimized design for dye removal to minimize contact time. Process Saf Environ Prot 76(4):313-318

Ho YS, Porter JF, McKay G (2001) Therefore the adsorption process is of a physical nature. Water Air Soil Pollut 141:1

Hosseini M, Mertens SFL, Ghorbani M, Arshadi MR (2003) Asymmetrical Schiff bases as inhibitors of mild steel corrosion in sulphuric acid media. Mater Chem Phys 78:800-808

Jones OAH, Voulvoulis N, Lester JN (2004) Potential ecological and human health risks associated with the presence of pharmaceutically active compounds in the aquatic environment. Crit Rev Toxicol 34(4):335-350 
Kyzas George Z, Koltsakidou Anastasia (2015) Removal of betablockers from aqueous media by adsorption onto graphene oxide. Sci Total Environ 537:411-420

Lagergren S (1898) About the theory of so-called adsorption of soluble substances. Kungliga Svenska Vetenskapsakademiens. Handlingar 24(4):1-39

Leite IF, Raposo CMO, Silva SML (2008) Caracterização estrutural de argilas bentoníticas nacional e importada: antes e após o processo de organofilização para utilização como nanocargas. Cerâmica 54(331):303-308

Lopez-Ramon MV, Stoeckli F, Moreno-Castilla C, Carrasco-Marin F (1999) On the characterization of acidic and basic surface sites on carbons by various techniques. Carbon 37:1215

Madejova J, Komadel P (2001) Baseline studies of the clay minerals society source clays: infrared methods. Clays Clay Miner 49(5):410-432

Margot J, Kienle C, Magnet A (2013) Treatment of micropollutants in municipal wastewater: ozone or powdered activated carbon. Sci Total Environ 461-462(06):480-498

Moore DM, Reynolds RC (1997) X-ray diffraction and the identification and analysis of clay minerals, 2nd edn. Oxford University Press, Oxford

Nanaki Stavroula G, Kyzas George Z (2015) Synthesis and characterization of modified carrageen an microparticles for the removal of pharmaceuticals from aqueous solutions. Coll Surf B 127:256-265
Polanyi M (1932) Section III.- - theories of the adsorption of gases. A general survey and some additional remarks. Introductory paper to section III. Trans Faraday Soc 28:316-333

Ramesh A, Lee DJ, Wong JWC (2005) Thermodynamic parameters for adsorption equilibrium of heavy metals and dyes from wastewater with low-cost adsorbents. J Coll Interf Sci 291(2):588-592

Rivera-Jiménez SM, Méndez-González S, Hernández-Maldonado A (2010) Metal $\left(\mathrm{M}=\mathrm{Co}^{2+}, \mathrm{Ni}^{2+}\right.$, and $\left.\mathrm{Cu}^{2+}\right)$ grafted mesoporous SBA-15: effect of transition metal incorporation and $\mathrm{pH}$ conditions on the adsorption of naproxen from water. Microporous Mesoporous Mater 132(3):470-479

Rytwo G, Ruiz-Hitzky E (2003) Enthalpies of adsorption of methylene blue and crystal violet to montmorillonite. J Therm Anal Calorim 71(3):751-759

Stipp SLS (1999) Toward a conceptual model of the calcite surface: hydration, hydrolysis, and surface potential. Geochim Cosmochim Acta 63(19):3121-3131

Turku I, Sainio T, Paatero E (2007) Thermodynamics of tetracycline adsorption on silica. Environ Chem Lett 5(4):225-228

Yadava KP, Tyagi BS, Singh VN (1991) Effect of temperature on the removal of lead (II) by adsorption on china clay and wollastonite. J Chem Technol Biotechnol 51(1):47-60

Yaneva Z, Koumanova B (2006) Comparative modelling of monoand dinitrophenols sorption on yellow bentonite from aqueous solutions. J Coll Interf Sci 293(2):303-311 